\title{
Promising polymer-assisted extraction of palladium from supported catalysts in supercritical carbon dioxide
}

Andrea Ruiu ${ }^{[a]}$, Bernhard Bauer-Siebenlist ${ }^{[b]}$, Marin Senila ${ }^{[c]}$, Thorsten Jänisch ${ }^{[d]}$, Dominique Foix ${ }^{[e]}$, Karine Seaudeau-Pirouley ${ }^{[f]}$, Patrick Lacroix-Desmazes $^{[a] *}$

[a] ICGM, Univ Montpellier, CNRS, ENSCM, Montpellier, France

[b] Heraeus Deutschland GmbH \& Co. KG, Heraeusstr. 12-14, 63450 Hanau, Germany

[c] National Institute for Research and Development of Optoelectronics Bucharest, Research Institute for Analytical Instrumentation, Donath 67, Cluj-Napoca, Romania

[d] Fraunhofer Institute for Chemical Technology ICT, Department Environmental Engineering, Group Reaction and Separation Techniques, Joseph-von-Fraunhofer-Str.7, 76327 Pfinztal, Germany

[e] Université de Pau et des Pays de l'Adour, E2S UPPA, CNRS, IPREM, Pau, France

[f] Innovation Fluides Supercritiques (IFS), Bâtiment INEED, 1 Rue Marc, Seguin, BP16109, 26300 Alixan, France

Dr.P. Lacroix-Desmazes* (Corresponding author) E-mail: patrick.lacroix-desmazes@enscm.fr 


\begin{abstract}
Precious metals, in particular palladium (Pd), have a wide range of daily applications, from automotive catalysts to fine chemistry production. Nevertheless, these metals are relatively rare and highly expensive, considering their massive industrial utilization. In the last decades, different recycling methods have been explored. Nowadays, the most applied methods, namely pyro- and/or hydrometallurgy, involve energy-intensive processes and/or the generation of large amounts of effluents to be treated. Thus, the development of a more sustainable recycling process of precious metals is highly desirable. In the present work, we introduce a sustainable process based on the use of a green solvent, supercritical $\mathrm{CO}_{2}$, operated under mild conditions $\left(\mathrm{P}=25 \mathrm{MPa}\right.$ and $\left.\mathrm{T}=40^{\circ} \mathrm{C}\right)$. The extraction process is possible thanks to the addition of $\mathrm{CO}_{2}$-soluble complexing polymers bearing pyridine units. The proposed method leads to the extraction of more than $70 \%$ of $\mathrm{Pd}$ from an aluminosilica-supported catalyst.
\end{abstract}

\title{
Graphical Abstract
}

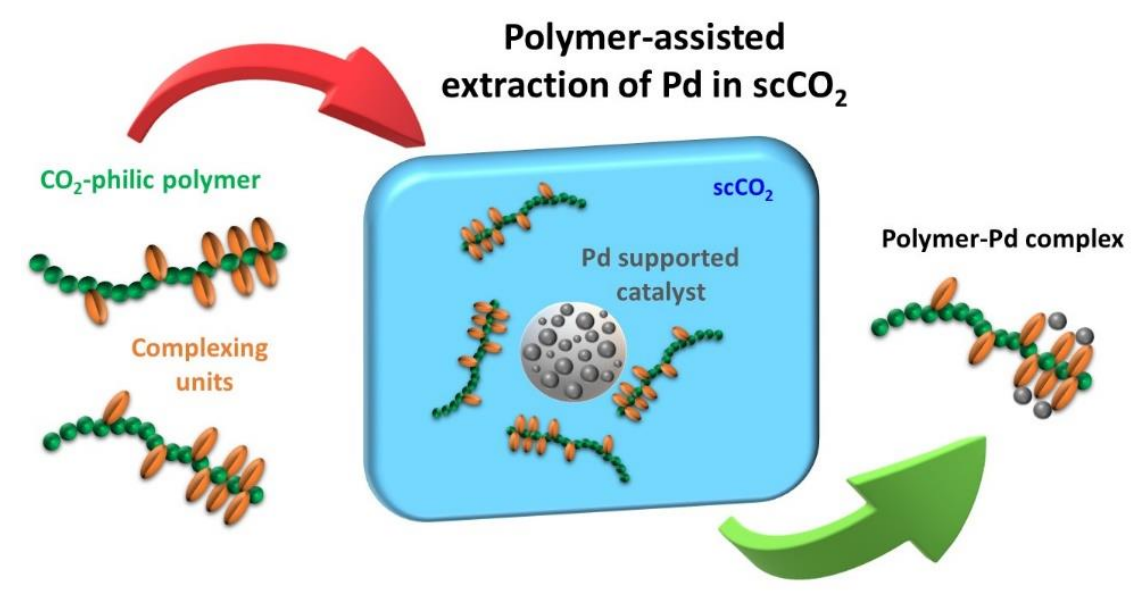

Keywords: catalyst; extraction; palladium; polymer; supercritical fluid

Short title: Palladium extraction in supercritical carbon dioxide 


\section{Introduction}

Precious metals play a key role in our daily lives. Owing to their unique properties, these elements find applications in a wide variety of industries and products, from petrochemistry to automotive applications. The yearly demand of precious metals is increasing due to industrial applications. In particular, the demand for palladium (Pd) has risen from 242 tons in 2010 to over 305 tons in 2018[1]. Despite the constantly growing demand of Pd over the past years, there is a supply deficit as mine production is not able to meet these demands, resulting in an increase in prices. For these reasons, alternative sources of the precious metal are necessary[2]. To date, the recovery of precious metals from spent catalysts has been performed with different techniques[3]. Pyrometallurgical and hydrometallurgical technologies, vacuum carbon-thermal reduction and high temperature incineration methods are the most commonly used techniques for the recycling of precious or critical metals and are thoroughly described in various reviews [2-4]. The aforementioned procedures require high temperatures (over $1000^{\circ} \mathrm{C}$ ) [5] or generate large amounts of effluents (usually strong acidic or basic solutions)[6]. This results in energy-intensive and environmentally hazardous processes.

Recently, different methods have been studied to recover precious metals from waste materials, involving technologies based on ionic liquids[7], polyphosphonates[8], ion exchange resins[9] or solvent extraction[10]. Thus, this research area is very active in the development of novel greener and safer methods to implement an improved and sustainable process to recover and recycle such precious metals.

An alternative procedure is the utilization of supercritical $\mathrm{CO}_{2}\left(\mathrm{scCO}_{2}\right)$ as extraction medium. $\mathrm{scCO}_{2}$ is considered a green solvent, characterized by its high availability and tunable solvent power. In addition, the supercritical domain can be achieved at mild conditions $\left(T_{c}=31^{\circ} \mathrm{C}, \mathrm{P}_{\mathrm{c}}=7.38 \mathrm{MPa}\right)$, making $\mathrm{scCO}_{2}$ an environmentally friendly and inexpensive medium for industrial applications. Being a nonpolar solvent, $\mathrm{scCO}_{2}$ is not effective by itself to perform metal extraction in the absence of proper additives that are able to interact with the precious metal. In the literature, dithiocarbamates, betadiketones, dithizone, and perfluorocarboxylic acids have been tested as complexing additives[11-15]. Thus, our group has recently proposed the development of a polymeric extractant soluble in $\mathrm{scCO}_{2}$, constituted by $\mathrm{CO}_{2}$-philic fragments (1,1,2,2-tetrahydroperfluorodecylacrylate, FDA) and complexing units (diphenylphosphinostyrene, DPPS)[16]. This first report showed the ability of this polymer to extract up to $50 \%$ of precious metal from an alumina-supported Pd catalyst.

In the present article, we present a novel extraction formulation to remove Pd from an aluminosilicasupported catalyst through the use of new $\mathrm{CO}_{2}$-soluble complexing polymers: poly(4-vinyl pyridinegrad-1,1,2,2-tetrahydroperfluorodecylacrylate) P(4VP-grad-FDA) and a thiol-terminated poly(4-vinyl pyridine-grad-1,1,2,2-tetrahydroperfluorodecylacrylate) P(4VP-grad-FDA)SH (Figure 1). These polymers contain pyridine complexing units able to interact with $\mathrm{Pd}$ species and $\mathrm{CO}_{2}$-philic $\mathrm{FDA}$ monomer units to confer solubility in $\mathrm{scCO}_{2}$. Although some non-fluorinated polymers such as siloxane-based $[17,18]$ or vinyl alkanoate-based $[19,20]$ polymers are soluble in $\mathrm{scCO}_{2}$, fluorinated FDAbased copolymers were chosen for this study because they usually exhibit exceptional solubility in dense $\mathrm{CO}_{2}$ with low sensitivity to molecular weight and nature of the chain-ends[21-23]. In contrast, non-fluorinated polymers are mostly soluble at low molecular weights and are sensitive to the nature of the chain-ends[24,25]. Moreover, we have focused on gradient copolymers instead of block copolymers because the latter usually require higher $\mathrm{CO}_{2}$ pressures to be solubilized in dense $\mathrm{CO}_{2}[26]$. This method is proposed as an alternative and innovative process to extract Pd from supported catalysts by using a green method, avoiding the use of high temperatures and the generation of hazardous effluents. 


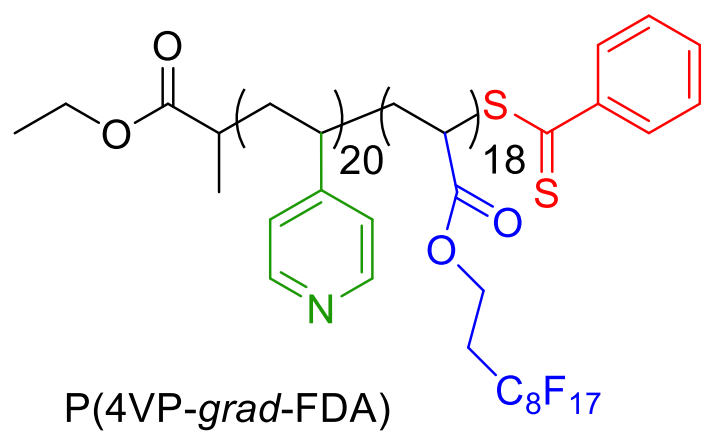

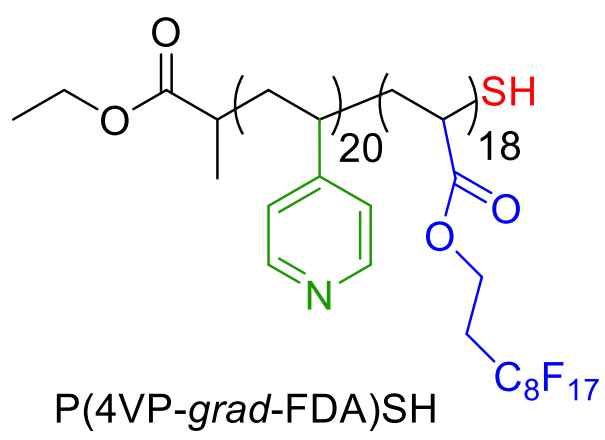

Figure 1. Structures of the gradient copolymers P(4VP-grad-FDA) and P(4VP-grad-FDA)SH used for the extractions of Pd from the supported catalysts.

\section{Experimental Section}

The catalysts used for these studies have been provided by Heraeus Deutschland GmbH \& Co. KG: pristine catalyst $D$ (CAT D), catalyst $D$ after reduction over 4 h under $\mathrm{H}_{2}$ atmosphere at $500{ }^{\circ} \mathrm{C}$ (CAT Dred), and catalyst $\mathrm{D}$ after reduction and subsequent oxidation over $4 \mathrm{~h}$ under $\mathrm{Cl}_{2}$ atmosphere at $470{ }^{\circ} \mathrm{C}$ (CAT D-ox) (Figure 2). CAT D is a pristine, industrial aluminosilica-supported catalyst used for the initial extraction experiments. This catalyst is similar to the common spent catalysts that Pd would normally be recycled from in terms of material and catalyst type, and therefore would help to reflect realistically on the performance of the extraction in industrial settings. The characterizations of the catalysts are reported in the supporting information (inductively coupled plasma optical emission spectrometry (ICP-OES), X-ray photoelectron spectroscopy (XPS), transmission electron microscopy (TEM), scanning electron microscopy with energy dispersive X-ray spectroscopy (SEM-EDX), nitrogen adsorptiondesorption isotherms (BET)). Carbon dioxide ( $\mathrm{CO}_{2}$, SFE 5.2, Air Liquide, 99.9\%) was used as received. The polymer synthesis has been performed following the procedures shown in the Supporting Information (SI), adapted from a previous work[27]. The polymer characterization is also shown in the $\mathrm{SI}$. The procedure for the extraction was as follows (Figure S1): catalyst $(\approx 200 \mathrm{mg}$ ) and P(4VP-gradFDA) ( $\approx 220 \mathrm{mg}$ ) were added in the $35 \mathrm{~mL}$ stainless-steel extraction cell (Top Industrie, France), which was then tightly closed. In the case of CAT D-ox, $0.02 \mathrm{~mL}$ of DIPEA ( $\mathrm{N}, \mathrm{N}$-diisopropylethylamine) were added to buffer the eventual release of $\mathrm{HCl}$ during the extraction (chlorine in $\mathrm{Na}_{2} \mathrm{PdCl}_{4}$ ). The ISCO pump was stabilized at $\mathrm{P}=27 \mathrm{MPa}$ and $\mathrm{T}=35^{\circ} \mathrm{C}$. Afterwards, the extraction cell was filled with $\mathrm{CO}_{2}$ until $25 \mathrm{MPa}$ at $40^{\circ} \mathrm{C}$ were reached in the cell. The extraction was performed under magnetic stirring at $100 \mathrm{rpm}$ for one hour at $25 \mathrm{MPa}$ and $40^{\circ} \mathrm{C}$ (batch conditions), and then the cell was flushed with 
$\approx 160 \mathrm{ml}$ of $\mathrm{CO}_{2}\left(26 \mathrm{MPa}\right.$ and $35^{\circ} \mathrm{C}$ in ISCO pump) at a flow rate of approximately $0.6-1.2 \mathrm{~mL} / \mathrm{min}$. Afterwards, the extraction cell was opened and the catalyst was recovered (Sample A). The cell was cleaned with acetone, which was subsequently collected and then evaporated (Sample B). Samples A and $\mathrm{B}$ were analysed by ICP-OES to determine the amount of precious metal extracted: Extraction conversion $(\%)=E(\%)=\left[1-\left(\right.\right.$ mass of $\mathrm{Pd}_{\text {sampleA }}+$ mass of $\left.\mathrm{Pd}_{\text {sampleB }}\right) /\left(\right.$ mass of $\left.\left.P \mathrm{~d}_{\text {initial catalyst }}\right)\right] \times 100$. As detailed in Table S1, the calculated extraction conversion (E \%) is related to the total mass of Pd (samples $A$ and $B$ ) left in the cell after extraction, therefore there is no further correction to apply. The errors bars $\triangle \mathrm{E} / \mathrm{E}(\%)$ on extraction conversion have been calculated considering the following accuracies: accuracy of weighing balance of $\pm 1 \mathrm{mg}$, ICP-OES measurements are accurate within $\pm 6 \%$.

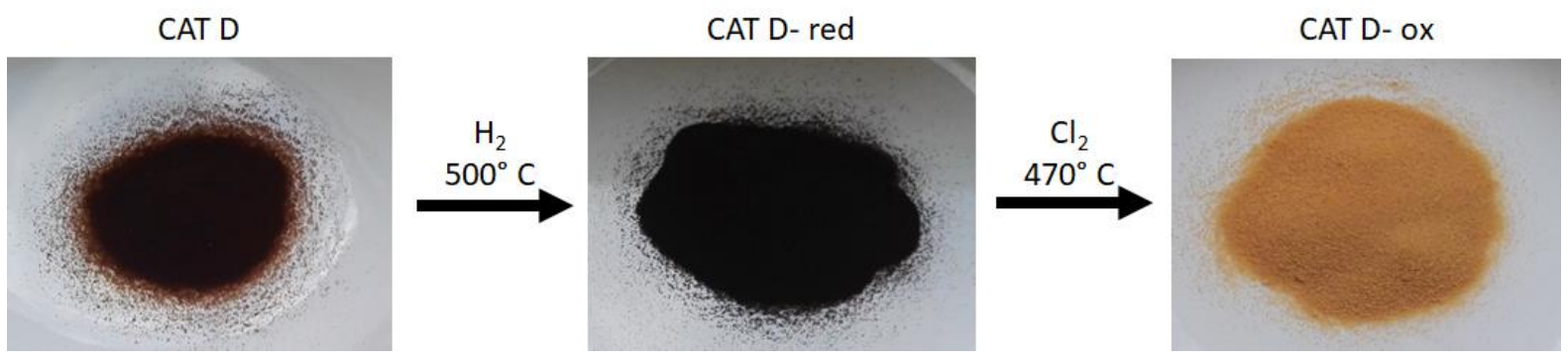

Figure 2. Pictures of the Pd supported catalysts CAT D, CAT D-red and CAT D-ox studied in this work.

\section{Results and discussion}

The catalysts used for these extraction experiments (CAT D, CAT D-red and CAT D-ox) were characterized through different analytical techniques to determine the concentration of the supported Pd (ICP-OES) and its oxidation state (XPS), the porosity of the catalyst (BET), the spatial distribution of the metal in the catalysts (SEM-EDX), and the metal particle size (TEM) (see the Supporting Information). All the catalysts have 2 wt\% of Pd (Tables S2-S3) and they are supported on an aluminosilica support (Table S4). For all the studied catalysts, the metal is present mainly on the surface of the support (Figures S2-S3); nonetheless, traces of metal could also be detected in the inner part of the material (Figure S4). The average pore size of the aluminosilica support is 21-22 nm, determined by nitrogen adsorption-desorption isotherms (BET) (Figures S5-S7, Table S5). Previous studies $[26,28]$ have shown that amphiphilic fluorinated polymers are prone to form micelles in $\mathrm{scCO}_{2}$. In particular, polymers weighing between 10 and $20 \mathrm{~kg} / \mathrm{mol}$ form micelles, with diameters in the order of $10 \mathrm{~nm}$. Thus, the pore diameter of the catalyst support is larger than the diameter of the micelles, allowing a proper interaction of the polymer with the precious metal even in the inner parts of the supported catalyst. All the supported catalysts used in this study have similar physical properties in terms of pore size and metal distribution. The main differences between the catalysts are the Pd oxidation states and the nature of the Pd species on the support, as well as the Pd particle size. CAT D contains palladium oxide PdO (100\%) (Figure S8), with an average particle size of $2.7 \mathrm{~nm}$ (Figure S9). CAT D-red contains $\mathrm{Pd}^{0}(79 \%)$ and $\mathrm{PdO}$ (21\%) (Figure S10), characterized by an increase of the average particle size, up to $3.3 \mathrm{~nm}$ (Figure S11). Finally, CAT D-ox contains mainly $\mathrm{Na}_{2} \mathrm{PdCl}_{4}$ (85\%) with a minor amount of PdO (15\%) (Figures S12-S13, Table S4). Consistently, in the case of CAT D-ox, TEM analysis showed the presence of a smaller amount of Pd particles at nanoscale dimensions, corresponding to the remaining PdO (Figure S14). Indeed, due to the low contrast of the $\mathrm{Na}_{2} \mathrm{PdCl}_{4}$ in TEM[29], it was not possible to see this salt which was adsorbed on the catalyst. 
The variation of the Pd oxidation state and the nature of the Pd species in the different catalysts are due to a pretreatment applied for the purpose of this work (Figure 2). The aim of modifying the oxidation state and the nature of the $\mathrm{Pd}$ species is to evaluate the efficiency of the extraction process on different $\mathrm{Pd}$ species $\left(\mathrm{Pd}(\mathrm{II}) \mathrm{O}, \mathrm{Pd}^{\circ}\right.$, and $\left.\mathrm{Na}_{2} \mathrm{Pd}(\mathrm{II}) \mathrm{Cl}_{4}\right)$ while keeping the same catalyst support (aluminosilicate) and metal distribution.

The polymers were synthesized by controlled radical polymerization using the reversible additionfragmentation chain transfer (RAFT) technique [27]. The Alfrey and Price $Q$ and e values of 4VP and FDA are available in the literature: $Q_{4 V P}=2.47$ and $e_{4 V P}=0.84[30], Q_{F D A}=0.44$ and $e_{F D A}=0.45[31]$. From these $Q$ and e values, the reactivity ratios could be estimated by using the classical Alfrey and Price equations[30]: $r_{4 V P}=4.05$ and $r_{F D A}=0.21$. Thus, $4 \mathrm{VP}$ is preferably introduced during copolymerization with FDA and there is a composition drift within the polymer chains (the beginning of the polymer chain is enriched in 4VP units), leading to a gradient copolymer structure for P(4VP-grad-FDA) (Figure S15) and P(4VP-grad-FDA)SH (Figure S16). The cloud point curves of the copolymers were determined in dense $\mathrm{CO}_{2}$ (Figure 3, Table S6). The copolymers were shown to be soluble in mild conditions of pressure, lower than $30 \mathrm{MPa}$ in the full range of temperatures from 25 to $65{ }^{\circ} \mathrm{C}$, as expected from previous works[26-28]. Notably, the aminolyzed copolymer P(4VP-grad-FDA)SH (Figure S16) has very similar cloud point pressures as its parent copolymer, indicating the negligible effect of the chain-end on the cloud point curve thanks to the high solubility of this kind of FDA-based fluorinated copolymer in dense $\mathrm{CO}_{2}$.

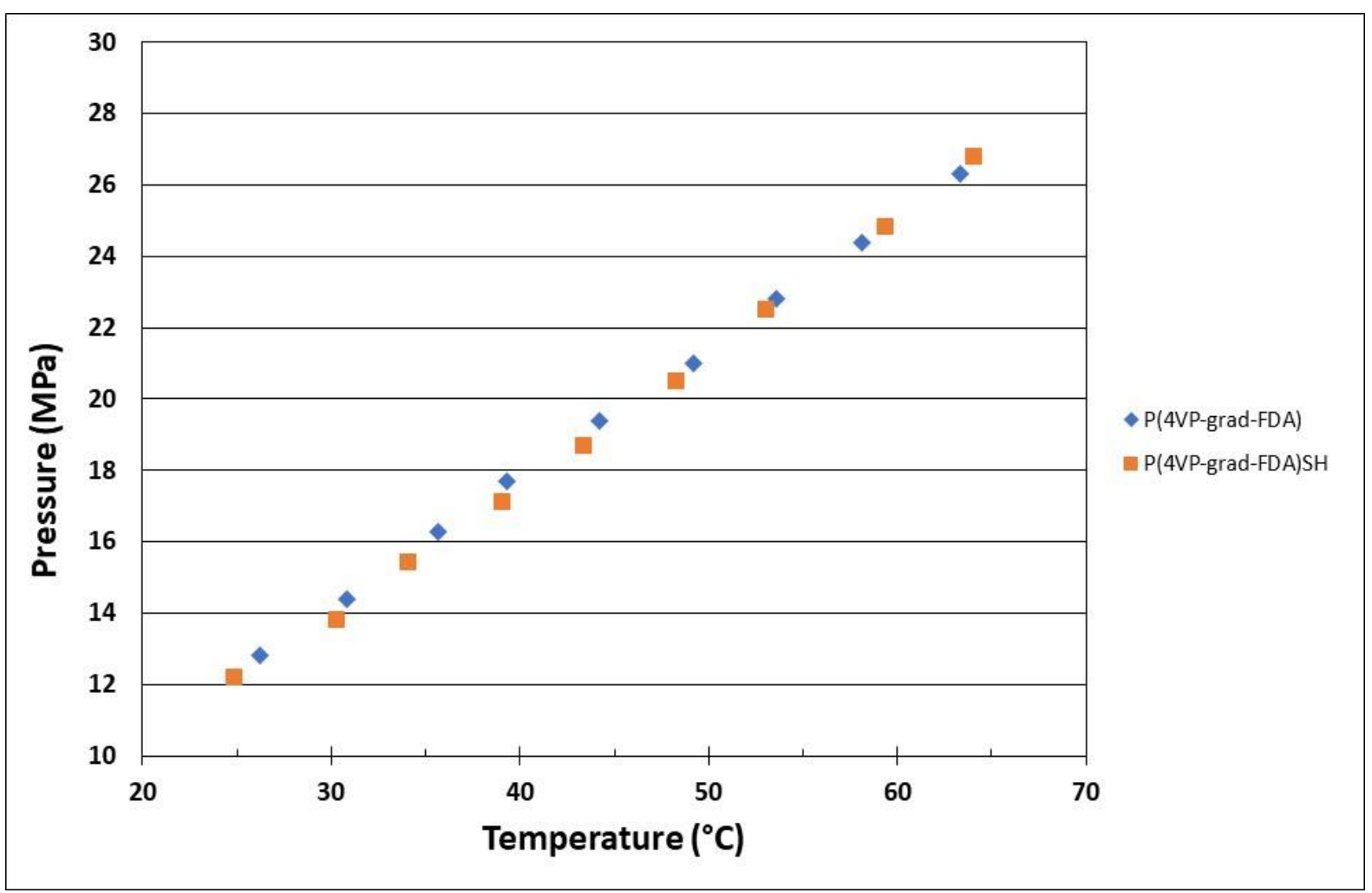

Figure 3. Cloud point curves of $\mathrm{P}(4 \mathrm{VP}$-grad-FDA) (diamond) and P(4VP-grad-FDA)SH (square) in dense $\mathrm{CO}_{2}$ (at a polymer concentration of $c a .1 \mathrm{wt} \%$ of polymer relative to $\mathrm{CO}_{2}$ ). 
The extraction procedure involves the use of mild supercritical operating conditions, at $\mathrm{P}=25 \mathrm{MPa}$ and $\mathrm{T}=40^{\circ} \mathrm{C}$, similar to those currently used for the decaffeination in $\mathrm{scCO}_{2}$ at industrial scale[32], making the metal extraction process potentially readily available for upscaling and commercial applications. Indeed, Manjare et al.[33] have reported that the relatively higher investment requirement in supercritical fluid extraction (SFE) processes is well compensated by several benefits, such as the low cost of $\mathrm{CO}_{2}$, shorter batch times, and negligible energy requirement of solvent recovery from the extract. In addition, there is no cost of pollution treatment since there is practically no effluent generated by SFE plants. In the present work, the conditions of temperature and pressure ( $P$ $=25 \mathrm{MPa}$ and $\mathrm{T}=40^{\circ} \mathrm{C}$ ) were chosen above the cloud point curve of the copolymers, ensuring that the copolymers are solubilized in $\mathrm{scCO}_{2}$ during the extraction process. The goal of the first experiments was to verify that the nonpolar $\mathrm{scCO}_{2}$ alone is unable to extract $\mathrm{Pd}$. Without polymer, for all the tested catalysts, less than $3 \%$ of Pd was removed from the catalyst support (Figure 4) (Table 1, runs E1, E4, E7), confirming the negligible solubility of the Pd species in neat $\mathrm{scCO}_{2}$ and the requirement of a complexing agent as additive.

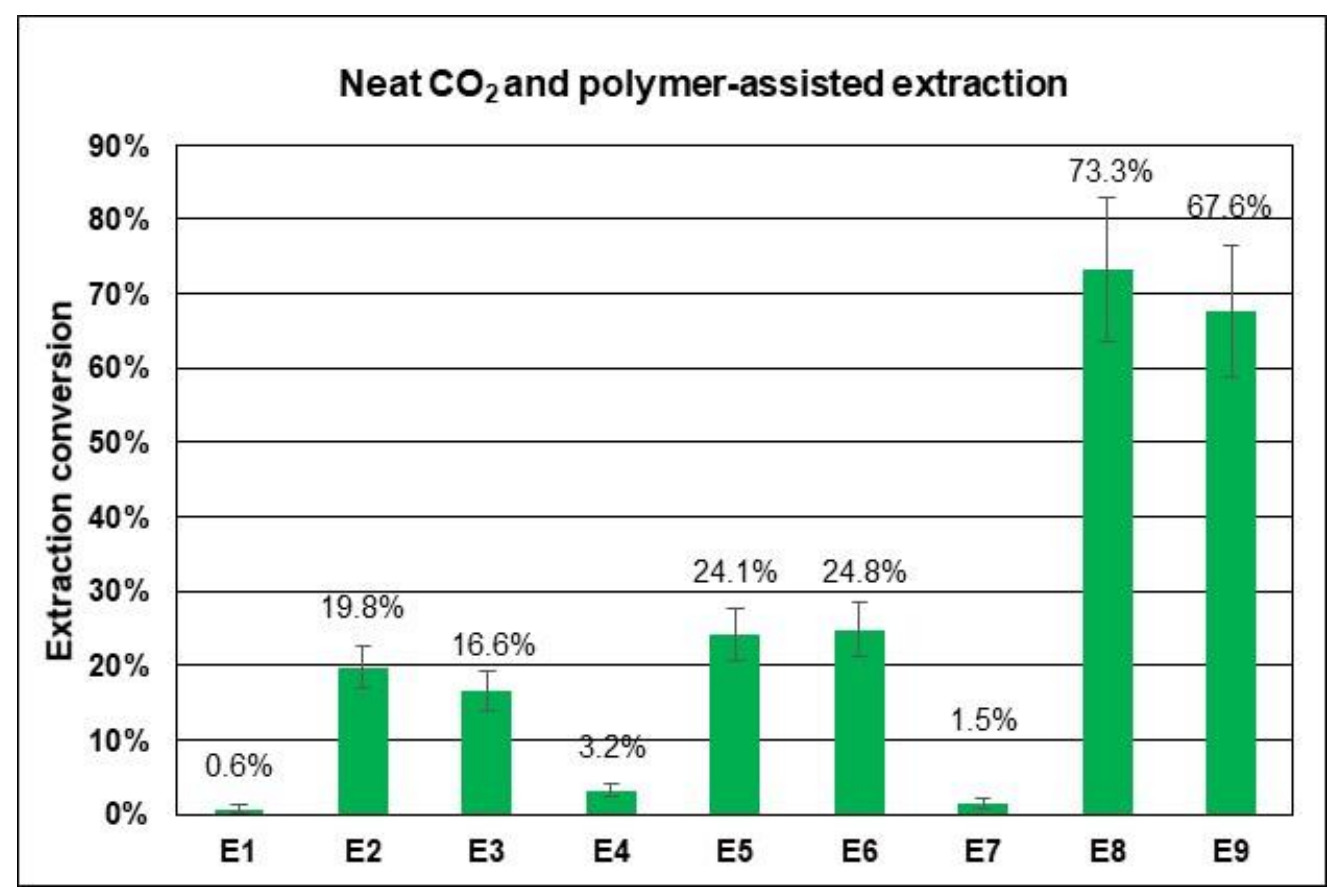

Figure 4. Extractions of palladium from CAT D (E1, E2, E3) , CAT D-red (E4, E5, E6) and CAT D-ox (E7, $E 8, E 9)$ in the absence of complexing polymer $(E 1, E 4, E 7)$ and in the presence of complexing polymers $\mathrm{P}(4 \mathrm{VP}$-grad-FDA $)(\mathrm{E} 2, \mathrm{E} 5, \mathrm{E} 8)$ and $\mathrm{P}\left(4 \mathrm{VP}\right.$-grad-FDA)SH (E3, E6, E9) in $\mathrm{ScCO}_{2}$ at $\mathrm{T}=40^{\circ} \mathrm{C}$ and $\mathrm{P}=25 \mathrm{MPa}$.

Subsequently, the extractions of $\mathrm{Pd}$ from the supported catalysts have been performed in $\mathrm{scCO}_{2}$ in the presence of $\mathrm{P}(4 \mathrm{VP}$-grad-FDA) as complexing agent (Figure 1$)$. As can be seen from the extraction tests with $\mathrm{CO}_{2}$ alone (E1, E4, E7), the polymer is fundamental for the metal extraction. This was expected as supercritical $\mathrm{CO}_{2}$ is a nonpolar system and consequently there is almost no chemical interaction between the metal and $\mathrm{CO}_{2}$. Therefore, it was decided to prepare a $\mathrm{CO}_{2}$-philic polymer bearing several pyridine units, well-known to interact and form complexes with metals like Pd and Pt[34-36].

The first polymer-assisted extraction experiments were performed at $25 \mathrm{MPa}$ and $40{ }^{\circ} \mathrm{C}$ on CAT D, CAT D-red and CAT D-ox with the polymer P(4VP-grad-FDA) (Table 1, runs E2, E5, E8). This complexing 
polymer $\left(\mathrm{M}_{\mathrm{n}} 11830 \mathrm{~g} / \mathrm{mol}\right)$ contains an average of 20 units of pyridine, allowing for good complexing ability, and 18 FDA units (Figure S15), necessary to obtain a polymer that is soluble in $\mathrm{scCO}_{2}$ under mild conditions of pressure. The extraction on CAT D showed low efficiency (19.8\%) (Figure 4 and Table 1, run E2), due to the strong interaction between PdO and the aluminosilica support as well as poor reactivity of such $\mathrm{Pd}$ derivatives toward organic ligands. With the reduced catalyst (Cat D-red) containing $\mathrm{Pd}^{0}$, the extraction was only slightly improved (24.1\%) (Figure 4, Table 1, run E5). The low efficiency of this polymer to interact with and remove the metal from the supported catalyst can be explained by the low affinity of the pyridine units as ligand in relation with the $\mathrm{Pd}^{0}$ nanoparticles. As shown in the Supporting Information, for both $\mathrm{PdO}$ and $\mathrm{Pd}^{0}$ loaded catalysts, the Pd nanoparticles on the aluminosilica support have a diameter in the order of $3 \mathrm{~nm}$. Presumably, the polar pyridine units favor the adsorption of the amphiphilic gradient copolymer on the surface of the Pd nanoparticles. Thus, thanks to the $\mathrm{CO}_{2}$-solubility of the polymer due to the FDA units, the $\mathrm{PdO}$ and $\mathrm{Pd}^{\circ}$ nanoparticles can be dispersed in $\mathrm{ScCO}_{2}$, with the polymer playing the role of a steric stabilizer (Figure 5a). It is important to notice the influence of the complexing polymer on the extraction process: in fact, the extraction of Pd increases from $0.6 \%$ and $3.2 \%$ (respectively for CAT D and CAT D-red without polymer) to $19.8 \%$ and $24.1 \%$ in the presence of the amphiphilic $\mathrm{CO}_{2}$-soluble polymer $\mathrm{P}(4 \mathrm{VP}$-grad-FDA) (Figure 4).

Finally, the polymer-assisted extraction procedure with the polymer P(4VP-grad-FDA) has been tested with the catalyst CAT D-ox, which contains mainly $\mathrm{Na}_{2} \mathrm{PdCl}_{4}$ (Figure 4 and Table 1, run E8). The extraction experiment led to a remarkable efficiency, allowing for the removal of $73.3 \%$ of the $\mathrm{Pd}$ absorbed on the catalyst. The successful Pd extraction can actually be observed visually by a change of color of the supported catalyst (Figure 6). As illustrated in Figure 2, the colored Pd species give the reddish-brown color to CAT D-ox (the aluminosilica support is white). In Figure 6, the reddish-brown color of CAT D-ox decreased after extraction because of the removal of the colored Pd species from the catalyst support. There was no significant volume nor mass change of the supported catalyst after extraction because there is only $2 \mathrm{wt} \% \mathrm{Pd}$ on the catalyst support. The improved result obtained with CAT D-ox can be explained by the enhanced reactivity of the $\mathrm{Na}_{2} \mathrm{PdCl}_{4}$ halogenated species with the pyridine ligand in comparison with the oxide (PdO) (CAT D) or metallic (Pd ${ }^{\circ}$ (CAT D-red) species. Indeed, halogenated Pd derivatives are commonly used as precursors in organometallic chemistry to synthesize novel complexes containing the precious metal[37-41]. Thus, the complexation of the precious metal by the polymer ligand sites, combined with the $\mathrm{CO}_{2}$-solubility of the polymer, makes the solubilization of the $\mathrm{Pd} /$ polymer supramolecular species and their transportation in the $\mathrm{scCO}_{2}$ medium possible, resulting in a promising polymer-assisted extraction of $\mathrm{Pd}$ from the aluminosilicasupport of the catalyst (Figure 5b). 


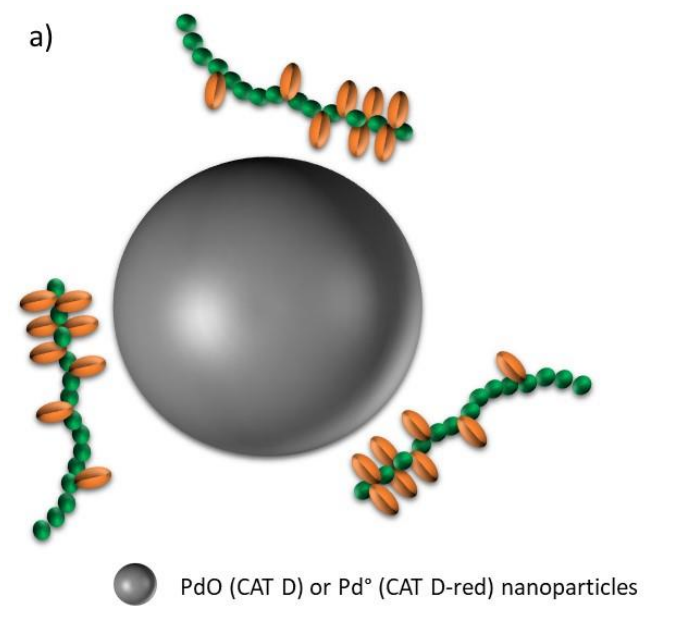

$\mathrm{Na}_{2} \mathrm{PdCl}_{4}\left(\right.$ or $\left.\mathrm{PdCl}_{2}\right)$ is the main form of Pd in CAT D-ox.

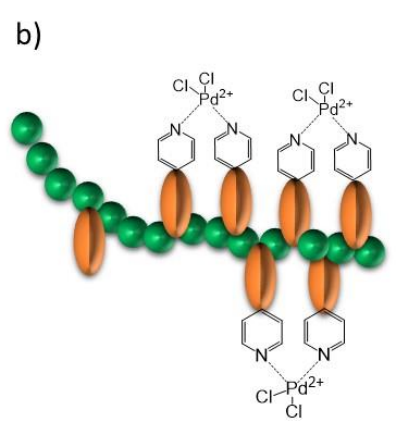

Complexing 4VP units

(2) $\mathrm{CO}_{2}$-philic FDA units

Figure 5. (a) Steric stabilization of the $\mathrm{PdO}$ or $\mathrm{Pd}^{\circ}$ metallic nanoparticles by the polymer P(4VP-gradFDA) in $\mathrm{ScCO}_{2}$ for the catalysts CAT D and CAT D-red; (b) formation of $\mathrm{CO}_{2}$-soluble supramolecular complexes Pd/P(4VP-grad-FDA) for the catalyst CAT D-ox.

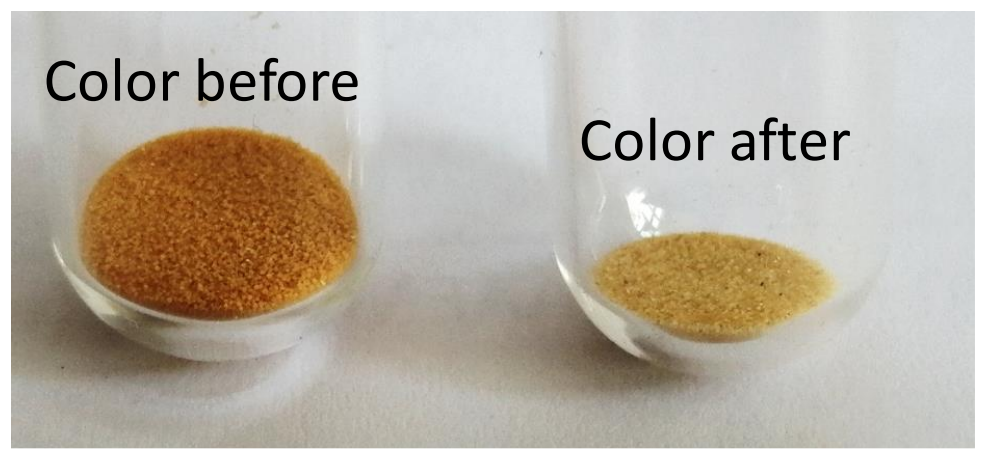

Figure 6. Change of color of the supported catalyst CAT D-ox after supercritical $\mathrm{CO}_{2}$ extraction of $\mathrm{Pd}$ assisted by the copolymer P(4VP-grad-FDA) at $40{ }^{\circ} \mathrm{C}$ and $25 \mathrm{MPa}$ : a) color of CAT D-ox before extraction; b) color CAT D-ox after extraction.

After these first experiments, the polymer $\mathrm{P}(4 \mathrm{VP}$-grad-FDA) has been modified by aminolysis in order to obtain $\mathrm{P}(4 \mathrm{VP}$-grad-FDA)SH (Figure 1), bearing a thiol end-group, thus providing a good $\mathrm{Pd}$ complexing unit to the polymer. This functionalization was performed to improve the metal extraction. Indeed, the sulphur-based molecules are well-known ligands for Pd species and are commonly used as complexing agents for metal recovery[42-44]. 
Table 1. Polymer-assisted extractions of Pd from aluminosilica-supported catalysts in supercritical $\mathrm{CO}_{2}$ at $\mathrm{T}=40{ }^{\circ} \mathrm{C}$ and $\mathrm{P}=25 \mathrm{MPa}^{[a]}$.

\begin{tabular}{|c|c|c|c|c|c|c|}
\hline Run & $\begin{array}{l}\text { Supported } \\
\text { catalyst }\end{array}$ & Polymer & $\begin{array}{c}\text { Complexing } \\
\text { group }\end{array}$ & $\begin{array}{l}\text { Polymer/Pd } \\
\text { molar ratio }\end{array}$ & $\begin{array}{l}\text { Complexing } \\
\text { group/Pd } \\
\text { molar ratio }\end{array}$ & $\begin{array}{l}\text { Extracted } \\
\text { Pd from } \\
\text { the } \\
\text { support of } \\
\text { the } \\
\text { catalyst } \\
(\%)^{[b]}\end{array}$ \\
\hline E1 & \multirow{3}{*}{ CAT D } & None & None & 0 & 0 & $0.6 \pm 0.6$ \\
\hline E2 & & $\begin{array}{c}\mathrm{P}\left(4 \mathrm{VP}_{18} \text {-grad- }\right. \\
\left.\mathrm{FDA}_{20}\right)\end{array}$ & $4 \mathrm{VP}$ & 0.56 & 11.1 & $19.8 \pm 2.9$ \\
\hline E3 & & $\begin{array}{c}\mathrm{P}\left(4 \mathrm{VP}_{18-} \text {-grad- }\right. \\
\left.\mathrm{FDA}_{20}\right) \mathrm{SH}\end{array}$ & $\begin{array}{l}4 \mathrm{VP} \\
\mathrm{SH}\end{array}$ & 0.50 & 10.5 & $16.6 \pm 2.6$ \\
\hline E4 & \multirow{3}{*}{ CAT D-red } & None & none & 0 & 0 & $3.2 \pm 0.9$ \\
\hline E5 & & $\begin{array}{c}\mathrm{P}\left(4 \mathrm{VP}_{18} \text {-grad- }\right. \\
\left.\mathrm{FDA}_{20}\right)\end{array}$ & $4 \mathrm{VP}$ & 0.55 & 11.1 & $24.1 \pm 3.5$ \\
\hline E6 & & $\begin{array}{c}\mathrm{P}\left(4 \mathrm{VP}_{18-} \text { grad- }\right. \\
\left.\mathrm{FDA}_{20}\right) \mathrm{SH}\end{array}$ & $\begin{array}{l}\text { 4VP } \\
\text { SH }\end{array}$ & 0.50 & 10.6 & $24.8 \pm 3.6$ \\
\hline E7 & \multirow{3}{*}{ CAT D-ox } & None & none & 0 & 0 & $1.5 \pm 0.7$ \\
\hline E8 & & $\begin{array}{c}\mathrm{P}\left(4 \mathrm{VP}_{18} \text {-grad- }\right. \\
\left.\mathrm{FDA}_{20}\right)\end{array}$ & $4 \mathrm{VP}$ & 0.56 & 11.2 & $73.3 \pm 9.6$ \\
\hline E9 & & $\begin{array}{c}\mathrm{P}\left(4 \mathrm{VP}_{18-} \mathrm{grad}_{-}\right. \\
\left.\mathrm{FDA}_{20}\right) \mathrm{SH}\end{array}$ & $\begin{array}{l}\text { 4VP } \\
\text { SH }\end{array}$ & 0.51 & 10.7 & $67.6 \pm 8.9$ \\
\hline
\end{tabular}

[a] General conditions: $m_{\text {catalyst }}=200 \mathrm{mg}, \mathrm{m}_{\text {polymer }}=220 \mathrm{mg}, \mathrm{mco}_{\text {, batch step }}=35 \mathrm{~g}$, mco2,flushing step $=145 \mathrm{~g}$.

[b] Determined by inductively coupled plasma - optical emission spectrometry (ICP-OES).

Unexpectedly, the extractions were not improved by the use of the thiol-terminated P(4VP-gradFDA)SH polymer as complexing agent (Figure 4, Table 1, runs E3, E6, E9). Therefore, the thiol group of $\mathrm{P}$ (4VP-grad-FDA)SH does not bring benefits to the steric stabilization of PdO (CAT D) and Pd (CAT Dred) nanoparticles, nor in the supramolecular complexation of $\mathrm{Na}_{2} \mathrm{PdCl}_{4}$ (CAT D-ox). In all cases, the contribution of the single thiol group is not significant enough compared to the $204 \mathrm{VP}$ units of the polymer chain.

The extraction conversion of 73\% obtained for CAT D-ox with P(4VP-grad-FDA) copolymer represents a promising polymer-assisted extraction of palladium from supported catalysts in $\mathrm{scCO}_{2}$. Indeed, even 
though the experimental conditions for the extraction have not been optimized yet, high extraction conversions have already been accomplished. Tan et al.[20] have reported high extraction conversions $(>70 \%)$ of $\mathrm{Ni}^{2+}, \mathrm{Co}^{2+}$ and $\mathrm{Cu}^{2+}$ by supercritical $\mathrm{CO}_{2}$ extraction assisted by oligo(vinyl acetate) bearing a bipyridine moiety, similar to those reported by our group[45] for cobalt extraction using a fluorinated polymer bearing phosphonic acid moieties; nevertheless, the support of the metal was not aluminosilica but filter paper[20] or cotton fabric,[45] respectively. In previous works of Pd extraction from supported catalysts in $\mathrm{scCO}_{2}$, even higher extraction conversions (up to 99\%) were obtained, but under optimized conditions and using hazardous chemicals like $\mathrm{HNO}_{3}[43,46,47]$. Compared to these earlier studies, the Pd extraction conversion of $73 \%$ obtained in the present work, without optimization and without generating hazardous waste streams, appears to be a very promising result. The amount of polymer used in run E8, leading to $73 \%$ extraction conversion, is $0.259 \mathrm{~g}$ of $\mathrm{P}(4 \mathrm{VP}$ grad-FDA) for $0.208 \mathrm{~g}$ of supported catalyst CAT D-ox. This weight ratio of polymer/catalyst of 1.2 is quite low compared to the amount of solvent used in hydrometallurgy where the liquid/solid ratio for leaching is typically in the range of 10[48]. The extraction methods such as pyrometallurgical processes and various hydrometallurgical and leaching methods[49] have been reviewed for the recovery of precious metals from supported catalysts[50,51]. Among them, alternative methods such as supercritical fluids extraction ( $\mathrm{scCO}_{2}$ and supercritical water), ionic liquid-assisted extraction[52], ultrasound-assisted pre-treatments for bioleaching[53] and microwave-assisted leaching[44] are considered to also have good potential to leach precious metals such as Pd. Nevertheless, there are still some challenges to achieving environment-friendly and sustainable recycling for precious metals with a high recovery rate. Thus, future technologies for precious metals recycling need to be more efficient and to have less environmental impact, lower cost, and higher recovery rate. In this context, polymer-assisted extraction in supercritical $\mathrm{CO}_{2}$ could be a way to avoid the use of low molecular weight, hazardous leaching agents.

As a conclusion, a promising method for the extraction of $\mathrm{Pd}$ from aluminosilica-supported catalysts in $\mathrm{scCO}_{2}$ under mild conditions $\left(\mathrm{P}=25 \mathrm{MPa}\right.$ and $\mathrm{T}=40{ }^{\circ} \mathrm{C}$ ) has been demonstrated by using a $\mathrm{CO}_{2}-$ soluble complexing polymer containing pyridine units $\mathrm{P}(4 \mathrm{VP}-$ grad-FDA). In this work, over $70 \%$ of the Pd precious metal has been removed from an aluminosilica support, by an environmentally friendly and non-destructive process, avoiding high energy demanding procedures or generation of polluting effluents. These studies will be pursued to further improve this extraction process, for instance through the use of different $\mathrm{CO}_{2}$-soluble complexing polymers (including non-fluorinated ones) and testing different extraction parameters (time, pressure, temperature). This method opens up the route for the development of a sustainable technology able to extract precious metals from porous supports, the first step of a recycling process with an increasing importance in modern industrial activities and in the emerging circular economy. Further steps will include the separation of Pd from the polymer-Pd mixture and the investigation of various methods for Pd recovery after its extraction by $\mathrm{SCCO}_{2}$. In addition, a comparative life cycle assessment (LCA)[54-56] between a conventional process and the process reported herein is envisioned to evaluate the technico-economical feasibility and the sustainability of the proposed polymer-assisted extraction process of precious metals in supercritical $\mathrm{CO}_{2}$ compared to other traditional methods.

\section{Acknowledgements}

The authors thank ANR (ANR-17-MIN2-0004-01), ADEME, Federal Ministry of Education and Research (grants number 033RU009A; 033RU009B), CCCDI-UEFISCDI (project number COFUND-ERANETERAMIN-SUPERMET, contract 48/2018) for financial support of the SUPERMET project 
(www.supermetproject.eu) in the frame of the ERA-MIN 2 joint call 2017 co-funded by the Horizon 2020 program of the European Union.

\section{References}

[1] Tanaka, PLATINUM AND PALLADIUM SURVEY 2019, 2019. https://newagemetals.com/wpcontent/uploads/GFMS_PGM_Survey_2019.pdf (accessed September 4, 2019).

[2] M. Wang, Q. Tan, J.F. Chiang, J. Li, Recovery of rare and precious metals from urban mines-A review, Front. Environ. Sci. Eng. 11 (2017) 1-17. doi:10.1007/s11783-017-0963-1.

[3] U. Jadhav, H. Hocheng, A review of recovery of metals from industrial waste, J. Achiev. Mater. 54 (2012) 159-167. http://ww.journalamme.org/papers_vol54_2/5422.pdf.

[4] H. Dong, J. Zhao, J. Chen, Y. Wu, B. Li, Recovery of platinum group metals from spent catalysts: A review, Int. J. Miner. Process. 145 (2015) 108-113. doi:10.1016/j.minpro.2015.06.009.

[5] Z. Peng, Z. Li, X. Lin, H. Tang, L. Ye, Y. Ma, M. Rao, Y. Zhang, G. Li, T. Jiang, Pyrometallurgical Recovery of Platinum Group Metals from Spent Catalysts, JOM. 69 (2017) 1553-1562. doi:10.1007/s11837-017-2450-3.

[6] H. Huang, C. Huang, Y. Wu, S. Ding, N. Liu, D. Su, T. Lv, Extraction of palladium(II) from nitric acid solutions with diglycolthioamide, Hydrometallurgy. 156 (2015) 6-11. doi:10.1016/j.hydromet.2015.05.002.

[7] A.P. Abbott, G. Frisch, J. Hartley, K.S. Ryder, Processing of metals and metal oxides using ionic liquids, Green Chem. 13 (2011) 471-481. doi:10.1039/c0gc00716a.

[8] O.C.S. Al Hamouz, S.A. Ali, Removal of heavy metal ions using a novel cross-linked polyzwitterionic phosphonate, Sep. Purif. Technol. 98 (2012) 94-101. doi:10.1016/j.seppur.2012.07.019.

[9] C.P. Gomes, M.F. Almeida, J.M. Loureiro, Gold recovery with ion exchange used resins, Sep. Purif. Technol. 24 (2001) 35-57. doi:10.1016/S1383-5866(00)00211-2.

[10] J. Nan, D. Han, X. Zuo, Recovery of metal values from spent lithium-ion batteries with chemical deposition and solvent extraction, J. Power Sources. 152 (2005) 278-284. doi:10.1016/j.jpowsour.2005.03.134.

[11] C.M. Wai, S. Wang, J.-J. Yu, Solubility Parameters and Solubilities of Metal Dithiocarbamates in Supercritical Carbon Dioxide, Anal. Chem. 68 (1996) 3516-3519. doi:10.1021/ac960276i. 
[12] E.B. Pereira, A.L. Suliman, E.H. Tanabe, D.A. Bertuol, Recovery of indium from liquid crystal displays of discarded mobile phones using solvent extraction, Miner. Eng. (2018) 67-72. doi:10.1016/j.mineng.2018.01.022.

[13] M.Z. Özel, M.D. Burford, A.A. Clifford, K.D. Bartle, A. Shadrin, N.G. Smart, N.D. Tinker, Supercritical fluid extraction of cobalt with fluorinated and non-fluorinated $\beta$-diketones, Anal. Chim. Acta. 346 (1997) 73-80. doi:10.1016/S0003-2670(97)00159-1.

[14] J. Halili, A. Mele, T. Arbneshi, I. Mazreku, Supercritical $\mathrm{CO}_{2}$ Extraction of Heavy Metals $\mathrm{Cu}, \mathrm{Zn}$ and Cd from Aqueous Solution using D ithizone as Chelating Agent, Am. J. Appl. Sci. 12 (2015) 284-289. doi:10.3844/ajassp.2015.284.289.

[15] S. Mochizuki, N. Wada, R.L. Smith Jr., H. Inomata, Supercritical fluid extraction of alkali metal ions using crown ethers with perfluorocarboxylic acid from aqueous solution, Anal. Commun. 36 (1999) 51-52. doi:10.1039/a808654k.

[16] W.S.J. Li, F. Gasc, J. Pinot, J. Causse, H. Poirot, J. Pinaud, C. Bouilhac, H. Simonaire, D. Barth, P. Lacroix-Desmazes, Extraction of palladium from alumina-supported catalyst in supercritical CO 2 using functional fluorinated polymers, J. Supercrit. Fluids. 138 (2018) 207-214. doi:10.1016/j.supflu.2018.04.013.

[17] I. Stoychev, F. Peters, M. Kleiner, S. Clerc, F. Ganachaud, M. Chirat, B. Fournel, G. Sadowski, P. Lacroix-Desmazes, Phase behavior of poly(dimethylsiloxane)-poly(ethylene oxide) amphiphilic block and graft copolymers in compressed carbon dioxide, J. Supercrit. Fluids. 62 (2012) 211218. doi:10.1016/j.supflu.2011.11.008.

[18] P.G. Parzuchowski, J. Gregorowicz, Z. Fras̈, E.P. Wawrzyńska, E. Brudzyńska, G. Rokicki, Hyperbranched poly(ether-siloxane) amphiphiles of surprisingly high solubility in supercritical carbon dioxide, J. Supercrit. Fluids. 95 (2014) 222-227. doi:10.1016/j.supflu.2014.08.030.

[19] D. Tapriyal, Y. Wang, R.M. Enick, J.K. Johnson, J. Crosthwaite, M.C. Thies, I.H. Paik, A.D. Hamilton, Poly(vinyl acetate), poly((1-O-(vinyloxy) ethyl-2,3,4,6-tetra-O-acetyl- $\beta$ - $d$ glucopyranoside) and amorphous poly(lactic acid) are the most $\mathrm{CO}_{2}$-soluble oxygenated hydrocarbon-based polymers, J. Supercrit. Fluids. 46 (2008) 252-257. doi:10.1016/j.supflu.2008.05.001.

[20] S. Zhang, Y. Luo, H. Yang, H.-J. Yang, B. Tan, Functional oligo(vinyl acetate) bearing bipyridine moieties by RAFT polymerization and extraction of metal ions in supercritical carbon dioxide, Polym. Chem. 4 (2013) 3507-3513. doi:10.1039/c3py00212h.

[21] P. Lacroix-Desmazes, P. Andre, J.M. Desimone, A.-V. Ruzette, B. Boutevin, Macromolecular surfactants for supercritical carbon dioxide applications: Synthesis and characterization of fluorinated block copolymers prepared by nitroxide-mediated radical polymerization, J. Polym. Sci. Part A Polym. Chem. 42 (2004) 3537-3552. doi:10.1002/pola.20193. 
[22] Z. Ma, P. Lacroix-Desmazes, Synthesis of hydrophilic $/ \mathrm{CO}_{2}$-philic poly(ethylene oxide)-bpoly(1,1,2,2-tetrahydroperfluorodecyl acrylate) block copolymers via controlled/living radical polymerizations and their properties in liquid and supercritical $\mathrm{CO}_{2}$, J. Polym. Sci. Part A Polym. Chem. 42 (2004) 2405-2415. doi:10.1002/pola.20117.

[23] P. André, P. Lacroix-Desmazes, D.K. Taylor, B. Boutevin, Solubility of fluorinated homopolymer and block copolymer in compressed $\mathrm{CO}_{2}$, J. Supercrit. Fluids. 37 (2006) 263-270. doi:10.1016/j.supflu.2005.08.007.

[24] Z. Shen, M.A. McHugh, J. Xu, J. Belardi, S. Kilic, A. Mesiano, S. Bane, C. Karnikas, E. Beckman, R. Enick, $\mathrm{CO}_{2}$-solubility of oligomers and polymers that contain the carbonyl group, Polymer (Guildf). 44 (2003) 1491-1498. doi:10.1016/S0032-3861(03)00020-X.

[25] D. Hu, Y. Zhang, M. Su, L. Bao, L. Zhao, T. Liu, Effect of molecular weight on $\mathrm{CO}_{2}$-philicity of poly(vinyl acetate) with different molecular chain structure, J. Supercrit. Fluids. 118 (2016) 96106. doi:10.1016/j.supflu.2016.07.024.

[26] T. Ribaut, J. Oberdisse, B. Annighofer, B. Fournel, S. Sarrade, H. Haller, P. Lacroix-Desmazes, Solubility and Self-Assembly of Amphiphilic Gradient and Block Copolymers in Supercritical CO 2, J. Phys. Chem. B. 115 (2011) 836-843. doi:10.1021/jp108888x.

[27] T. Ribaut, P. Lacroix-Desmazes, B. Fournel, S. Sarrade, Synthesis of gradient copolymers with complexing groups by RAFT polymerization and their solubility in supercritical $\mathrm{CO} 2$, J. Polym. Sci. Part A Polym. Chem. 47 (2009) 5448-5460. doi:10.1002/pola.23594.

[28] T. Ribaut, J. Oberdisse, B. Annighofer, I. Stoychev, B. Fournel, S. Sarrade, P. Lacroix-Desmazes, SANS study of the self-organization of gradient copolymers with ligand groups in supercritical $\mathrm{CO}_{2}$, Soft Matter. 5 (2009) 4962-4970. doi:10.1039/b912268k.

[29] Y. Hong, A. Sen, Selective Heterogeneous Catalytic Hydrogenation by Recyclable Poly(allylamine) Gel-Supported Palladium(0) Nanoparticles, Chem. Mater. 19 (2007) 961-963. doi:10.1021/CM062526+.

[30] G. Odian, Chain Polymerization, in: Princ. Polym., Forth edit, John Wiley \& Sons, Inc., 2004: pp. 500-502.

[31] B. Guyot, B. Boutevin, Détermination des coefficients d'Alfrey et Price de monomères acryliques fluorés et du méthacrylate de morpholinoéthyle, Eur. Polym. J. 32 (1996) 751-756. doi:10.1016/0014-3057(95)00191-3.

[32] E. Lack, H. Seidlitz, Commercial scale decaffeination of coffee and tea using supercritical $\mathrm{CO}_{2}$, in: Extr. Nat. Prod. Using Near-Critical Solvents, Springer Netherlands, Dordrecht, 1993: pp. 101-139. doi:10.1007/978-94-011-2138-5_5. 
[33] S.D. Manjare, K. Dhingra, Supercritical fluids in separation and purification: A review, Mater. Sci. Energy Technol. 2 (2019) 463-484. doi:10.1016/j.mset.2019.04.005.

[34] M.M. Matlock, B.S. Howerton, K.R. Henke, D.A. Atwood, A pyridine-thiol ligand with multiple bonding sites for heavy metal precipitation, J. Hazard. Mater. 82 (2001) 55-63. doi:10.1016/\$0304-3894(00)00353-8.

[35] T. Tu, X. Feng, Z. Wang, X. Liu, A robust hydrophilic pyridine-bridged bis-benzimidazolylidene palladium pincer complex: Synthesis and its catalytic application towards Suzuki-Miyaura couplings in aqueous solvents, Dalt. Trans. 39 (2010) 10598-10600. doi:10.1039/c0dt01083a.

[36] G.R. Newkome, V.K. Gupta, F.R. Fronczek, Chemistry of heterocyclic compounds. 81. Palladium(II) complexes of pyridine- and pyrazine-based ligands with trans bis(carbon-metal) bonds. Ligand synthesis, complexation, and crystal structure, Organometallics. 1 (1982) 907910. doi:10.1021/om00067a004.

[37] S. Dey, V.K. Jain, J. Singh, V. Trehan, K.K. Bhasin, B. Varghese, Pyridine- and 3-/6Methylpyridine-2-tellurolate Complexes of Palladium(II) and Platinum(II), Eur. J. Inorg. Chem. 2003 (2003) 744-750. doi:10.1002/ejic.200390103.

[38] S.R. Batten, J.C. Jeffery, A.M.W. Cargill Thompson, L.H. Rees, M.D. Ward, Some Coordination Chemistry of the Bidentate Nitrogen-Donor Ligand 2-(2-Aminophenyl)pyridine, Artic. Aust. J. Chem. 50 (1997) 109-114. doi:10.1071/C96146.

[39] Z. Ye, B. Zhang, L. Shao, G. Xing, C. Qi, H. Tao, Palladium nanoparticles embedded chitosan/poly(vinyl alcohol) composite nanofibers as an efficient and stable heterogeneous catalyst for Heck reaction, J. Appl. Polym. Sci. 136 (2019) 48026-48032. doi:10.1002/app.48026.

[40] W. Solodenko, U. Schön, J. Messinger, A. Glinschert, A. Kirschning, Microwave-Assisted SuzukiMiyaura Reactions with an Insoluble Pyridine-Aldoxime Pd-Catalyst, Synlett. (2004) 16991702. doi:10.1055/s-2004-829546.

[41] K. Ha, A second monoclinic polymorph of (pyridine-2-carboxaldehyde oximato-k $2 \mathrm{~N}, \mathrm{~N}$ ')(pyridine-2-carboxaldehyde oxime-k $2 \mathrm{~N}, \mathrm{~N}$ ')palladium(II) chloride, Acta Crystallogr. Sect. E Struct. Reports Online. 68 (2012) m176-m177. doi:10.1107/S1600536812001559.

[42] D. Ko, J.S. Lee, H.A. Patel, M.H. Jakobsen, Y. Hwang, C.T. Yavuz, H.C.B. Hansen, H.R. Andersen, Selective removal of heavy metal ions by disulfide linked polymer networks, J. Hazard. Mater. 332 (2017) 140-148. doi:10.1016/j.jhazmat.2017.03.007.

[43] S. Iwao, S. Abd El-Fatah, K. Furukawa, T. Seki, M. Sasaki, M. Goto, Recovery of palladium from spent catalyst with supercritical $\mathrm{CO}_{2}$ and chelating agent, J. Supercrit. Fluids. 42 (2007) 200204. doi:10.1016/j.supflu.2007.03.010. 
[44] T. Suoranta, O. Zugazua, M. Niemelä, P. Perämäki, Recovery of palladium, platinum, rhodium and ruthenium from catalyst materials using microwave-assisted leaching and cloud point extraction, Hydrometallurgy. 154 (2015) 56-62. doi:10.1016/j.hydromet.2015.03.014.

[45] M. Chirat, T. Ribaut, S. Clerc, F. Charton, B. Fournel, P. Lacroix-Desmazes, Extraction of Cobalt Ion from Textile Using a Complexing Macromolecular Surfactant in Supercritical Carbon Dioxide, Ind. Eng. Chem. Res. 52 (2012) 538-542. doi:10.1021/ie301754v.

[46] J.S. Wang, C.M. Wai, Dissolution of precious metals in supercritical carbon dioxide, Ind. Eng. Chem. Res. 44 (2005) 922-926. doi:10.1021/ie040198m.

[47] M. Faisal, Y. Atsuta, H. Daimon, K. Fujie, Recovery of precious metals from spent automobile catalytic converters using supercritical carbon dioxide, Asia-Pacific J. Chem. Eng. 3 (2008) 364367. doi:10.1002/apj.156.

[48] D. Fontana, M. Pietrantonio, S. Pucciarmati, G.N. Torelli, C. Bonomi, F. Masi, Palladium recovery from monolithic ceramic capacitors by leaching, solvent extraction and reduction, J. Mater. Cycles Waste Manag. 20 (2018) 1199-1206. doi:10.1007/s10163-017-0684-3.

[49] Y. Ding, H. Zheng, J. Li, S. Zhang, B. Liu, C. Ekberg, An Efficient Leaching of Palladium from Spent Catalysts through Oxidation with Fe(III), Materials (Basel). 12 (2019) 1205-1217. doi:10.3390/ma12081205.

[50] C. Saguru, S. Ndlovu, D. Moropeng, A review of recent studies into hydrometallurgical methods for recovering PGMs from used catalytic converters, Hydrometallurgy. 182 (2018) 44-56. doi:10.1016/j.hydromet.2018.10.012.

[51] Y. Ding, S. Zhang, B. Liu, H. Zheng, C. chi Chang, C. Ekberg, Recovery of precious metals from electronic waste and spent catalysts: A review, Resour. Conserv. Recycl. 141 (2019) 284-298. doi:10.1016/j.resconrec.2018.10.041.

[52] M.L. Firmansyah, F. Kubota, M. Goto, Selective recovery of platinum group metals from spent automotive catalysts by leaching and solvent extraction, J. Chem. Eng. Japan. 52 (2019) 835842. doi:10.1252/jcej.19we093.

[53] S. Karim, Y.P. Ting, Ultrasound-assisted nitric acid pretreatment for enhanced biorecovery of platinum group metals from spent automotive catalyst, J. Clean. Prod. 255 (2020) 120199120212. doi:10.1016/j.jclepro.2020.120199.

[54] I. De Marco, S. Riemma, R. lannone, Life cycle assessment of supercritical $\mathrm{CO}_{2}$ extraction of caffeine from coffee beans, J. Supercrit. Fluids. 133 (2018) 393-400. doi:10.1016/j.supflu.2017.11.005.

[55] M. Ghodrat, M.A. Rhamdhani, P. Sharafi, B. Samali, A Comparative Life Cycle Assessment of 
Recycling the Platinum Group Metals from Automobile Catalytic Converter: An Australian Perspective, Metall. Mater. Trans. E. 4 (2017) 77-88. doi:10.1007/s40553-017-0109-1.

[56] M.N. Le, M.S. Lee, A Review on Hydrometallurgical Processes for the Recovery of Valuable Metals from Spent Catalysts and Life Cycle Analysis Perspective, Miner. Process. Extr. Metall. Rev. 00 (2020) 1-20. doi:10.1080/08827508.2020.1726914. 